\title{
The Pivot in Chinese Cybergovernance
}

Integrating Internet Control in Xi Jinping's China

\section{Rogier Creemers}

\section{OpenEdition}

\section{Journals}

Electronic version

URL: http://journals.openedition.org/chinaperspectives/6835

ISSN: 1996-4617

\section{Publisher}

Centre d'étude français sur la Chine contemporaine

\section{Printed version}

Date of publication: 1 December 2015

Number of pages: 5-13

ISSN: 2070-3449

\section{Electronic reference}

Rogier Creemers, «The Pivot in Chinese Cybergovernance », China Perspectives [Online], 2015/4 | 2015, Online since 01 January 2017, connection on 28 October 2019. URL : http://journals.openedition.org/ chinaperspectives/6835 


\title{
The Pivot in Chinese
}

\section{Cybergovernance}

\author{
Integrating Internet Control in Xi Jinping's China
}

\section{ROGIER CREEMERS}

\begin{abstract}
During the first two years of the Xi administration, a series of successive measures were taken to restructure the way that the Chinese Internet is governed. New institutions were created to centralise governance over a sphere that had hitherto been fragmented, while the pursuit of ideological and technological security led to greater efforts to control the circulation of online information and prevent harm, particularly originating from foreign threats. This paper analyses this process, and discusses implications for the future of the Chinese and global Internet.
\end{abstract}

KEYWORDS: Internet governance, political reform, media, security, ideology.

\section{Introduction}

T he Internet has become a central element of the Chinese government's ambitious reform agenda as presented in the Third and Fourth Plenums of the $18^{\text {th }}$ Party Congress. In March 2015, Premier Li Keqiang unveiled the "Internet Plus" plan, an ambitious agenda that leverages the power of information technology for economic growth and development. (1) A specific, elaborate implementation plan was published in July. (2) Similar, more detailed plans address the development of sectors as diverse as e-commerce, online finance, and tech entrepreneurship. Big data has been enlisted in an effort to enhance the Party's governing ability.

Nevertheless, following the accession of the Xi leadership in 2012, the Internet and information technology were viewed with considerable suspicion. Social media had provided a platform for raucous political debate, criticism of Party authorities and revelation of corruption and official abuses. It was also seen as a channel for "foreign hostile forces" (guowai didui shili 国外敌对势力) to undermine China's political stability. Consequently, significant institutional, regulatory and policy changes were made in order to regain control over the Internet and pave the way for the strategies outlined above. A new Central Committee apparatus was created, led by Xi Jinping personally. Second, new rules were introduced for the domestic Internet, ranging from social media and audio-visual content to technology suppliers.

This paper will review these changes and discuss their implications for the role of the Internet in governance and social management. This taps into two academic debates and two important policy areas that are increasingly coalescing: the notion of the Internet as a space for communication and organisation on the one hand, and information technology as a facilitator of government intervention, surveillance, and control on the other.

Increasing censorship during the second half of the Hu era notwithstanding, the Internet became a vibrant space for social interaction and public exchange with, as Hu Yong phrases it, a "cacophony" (xuanhua 喧华) of voices. ${ }^{(3)}$ Scholars have disagreed about the degree of intentionality with which this space was created or condoned. Jonathan Sullivan, for instance, claims that social media tools enabled the Party to better monitor its agents and respond to particular, specific concerns while ignoring their systemic causes. ${ }^{(4)}$ Rebecca MacKinnon, for instance, argues that Internet blogs could serve as a "safety valve" by permitting opinions and dissent to be vented before they transform into mobilisation or political action. ${ }^{(5)}$ Others, such as Milton Mueller (6) and Li Yonggang, ${ }^{(7)}$ argue that the state's response to Internet developments was more characterised by improvisation and learning in continuously changing contexts. Nevertheless, most scholars agreed that the leadership's attitude towards the public discourse element of the Internet, and particularly social media, was ambivalent. In Alice Miller's view, this was one of the major symptoms of the political stasis that characterised the second half of the Hu administration. ${ }^{(8)}$

The research for this paper was funded with a Rubicon grant from the Netherlands Organisation for Scientific Research (NWO)

1. 2015 nian zhengfu gongzuo baogao" (2015 Government Work Report), presented to the Plenary Session of the National People's Congress, 5 March 2015, http://lianghui.people.com.cn/2015npc/ n/2015/0305/c394298-26642056.html (all URLs accessed on 30 October 2015).

2. State Council, "Guanyu jiji tuijin 'Hulianwang+' xingdong de zhidao yijian" (Guiding Opinions Concerning Vigorously Promoting "Internet Plus" Activities), 5 July 2015.

3. Hu Yong, Zhongsheng xuanhua: wangluo shidai de geren biaoda yu gongong taolun (A Cacophony of Mass Voices: Personal Expression and Public Debate in the Network Age), Guilin, Guangxi Normal University Press, 2008.

4. Jonathan Sullivan, "China's Weibo: Is faster different?", New Media \& Society, Vol. 16, No. 1, 2014.

5. Rebecca MacKinnon, "China's 'networked authoritarianism'," Journal of Democracy, Vol. 22, No. 2, 2011. See also Jonathan Hassid, "Safety valve or pressure cooker? Blogs in Chinese political life," Journal of Communication, Vol. 62, No. 2, 2012.

6. Milton L. Mueller, "China and Global Internet Governance: A Tiger by the Tail," in Ronald Deibert et al. (eds), Access Contested: Security, Identity, and Resistance in Asian Cyberspace, Cambridge, MIT Press, 2012.

7. Cited in Rebecca MacKinnon, "Chinese Internet Research Conference: Getting beyond 'Iron Curtain 2.0'," RConversation, 18 June 2008, http://rconversation.blogs.com/rconversation/2008/06/chinese-inter-1.html (accessed on 21 November 2015).

8. Alice Miller, "The Trouble with Factions," China Leadership Monitor, No. 46, 2015. 
Such ambivalence is completely absent from the state's stance on the technological and economic aspects of Internet development. As Gudrun Wacker already claimed in 2003, a Promethean optimism about the transformative role of technology in development, going back to the early days of industrialisation in late-Qing China, is common in Chinese governing circles. ${ }^{(9)}$ Through state-funded initiatives, such as the 863 programme and the indigenous innovation agenda, China has sought to rapidly enhance domestic high-tech capabilities. Informatisation (xinxihua 信息化), the process of enhancing economic efficiency, improving governance, and strengthening social services through the application of information technologies, has been a priority for more than a decade. (10) Information technology was listed among the "Four New Modernisations" that the new leadership put forward in January 2013, mere weeks after its installation. (11) As Duan Qing demonstrates, the pursuit of informatisation has also influenced the interaction between the leadership and private enterprise, enabling the rise of a class of IT leaders. These leaders do not pose a direct challenge to the regime, and in fact, have mutually overlapping interests in fostering economic growth and strong domestic companies. Nevertheless, they do constitute a somewhat autonomous community, making possible a considerable presence of private actors in an economic sphere critical to political stability: the Internet is the only "commanding height" (zhigaodian 制高点) where large private enterprises play a significant role. ${ }^{12)}$ Yet here also, the authoritarian calculus influences outcomes. As Greg Austin claims, overriding concerns about information control have stunted the development of the information society. Often merited distrust about government-produced content created a toxic environment "awash in supposition, half-credible news stories and libel," (13) while the state security system has consistently undermined the development of security technology and encryption, contributing to a growing cybercrime scourge.

This paper will argue that the changes brought by the Xi administration sought to achieve three major goals. First, with regard to social media, it sought to change the public nature of the online sphere, ending the ambivalence of the Hu era. The potential for mobilisation, association, and large-scale communication on social media was seen as a potential risk, yet at the same time provided valuable information on public opinion to the leadership. Consequently, instead of largely open and interactive media, such as Weibo, the leadership implicitly supported more private platforms, such as WeChat, where surveillance remains possible. Second, the administrative restructuring of the Internet governance apparatus can be seen as an effort to centralise leadership over this important sphere, transcending interdepartmental boundaries and interests, and creating direct links to the summit of political power. Lastly, the efforts intended to signal the importance the leadership attributes to information technology, and to lay the groundwork for the continued and accelerated adoption of information technology in all areas of socio-economic governance.

\section{Organisational change}

The Xi administration took two major organisational steps in its reform of Internet governance. First, it established a presidential-level policy coordination unit called the Central Leading Group for Cybersecurity and Informatisation. Second, it greatly enhanced the authority of the State Internet Information Office. These two bodies have separate, but interrelated lineages. The Central Leading Group is the latest iteration of an organisa- tional reform process that sought to lead and coordinate the development of China's information society, including technological development, economic success, and security, as well as online content. The State Internet Information Office, on the other hand, was established within the propaganda apparatus in order to provide a more coherent basis for the control of online content. ${ }^{(14)}$ These two bodies have been combined into a structure not unlike other Party-state "systems" (xitong 系统). ${ }^{(15)}$ The process of transformation is nevertheless unfinished, and it remains to be seen exactly how decision-making patterns and powers crystallise.

As Internet technology developed, various pieces of its functionality came under the purview of actors from different "systems." Some of the first rules on Internet use were promulgated by the Ministry of Public Security, as these concerned the integrity and security of information networks. ${ }^{(16)}$ Reflecting the Internet's roots in scientific research, the China Internet Network Information Centre (CNNIC) was established under the aegis of the Chinese Academy of Science and the Ministry of Information Industry (MII). The CNNIC is responsible for domain name registration and IP address allocation, as well as the issuance of trust certificates. The emergence of an Internet economy largely dominated by private enterprises led to the establishment of the Internet Society of China in 2001. The ISC acts as an intermediary organ linking the Internet industry to government, and has a regulatory role through the self-disciplinary documents it publishes. On the governmental side, a new ministry in charge of telecommunications, the Ministry of Information Industry, was created in 1998 through the merger of, amongst others, the Ministry of Post and Telecommunications and the Ministry of Electronics Industry. Furthermore, different functional bodies, including the State Administration of Radio, Film, and Television (SARFT) and the General Administration of Press and Publications (GAPP), were given primary review powers.

A successive series of bodies was established to lead and coordinate the activities of these bodies, with their portfolio growing and their bureaucratic position increasing as time went by. A pre-existing interministerial joint conference was transformed into the State Council Leading Group for Informatisation Work (Guowuyuan xinxihua gongzuo lingdao xiaozu 国务

9. Christopher Hughes and Gudrun Wacker, "China's Digital Leap Forward," in Christopher Hughes and Gudrun Wacker, China and the Internet: Politics of the Digital Leap Forward, Abingdon, Routledge, 2003.

10. Generally, Eric Harwit, China's Telecommunications Revolutions, Oxford, Oxford University Press, 2008. For an internal point of view, see Qu Weizhi, China's Path to Informatization, Singapore, Cengage, 2010

11. "Meiti xi 'xinsihua' xinyi: cong yi wu wei zhu zhuanxiang yi ren wei ben" (Media Analysis of the New Meanings of the "New Four Modernizations": From Giving First Place to Materials to Putting People First), People's Daily, 17 January 2013, translation available at https://chinacopyrightandmedia.wordpress.com/2013/01/17/media-analysis-of-the-new-meanings-of-the-new-four-modernizations-from-giving-first-place-to-materials-to-putting-people-first.

12. Duan Qing, China's IT Leadership: The Political Struggle behind China's Information Revolution, Saarbrücken, VDM Verlag, Müller, 2007.

13. Greg Austin, Cyber Policy in China, Cambridge \& Malden, Polity Press, 2014, p. 80.

14. As People's Daily reported at the SIIO's establishment, the Internet had hitherto been managed "like nine dragons managing the water" (jiulong zhishui). Chen Zhenkai, "Zhongguo hulianwang guanli jiang dapo 'jiulong zhishui' geju" (The Situation of "Nine Dragons Coverning the Water" in China's Internet Management Will Be Smashed), People's Daily Overseas Edition, 5 May 2011.

15. Tony Saich defines xitong in the broad sense as functionally related bureaucracies that cross individual ministry or industry lines, which coordinate policy and attempt to monitor its implementation, and link to leadership groups at the Centre. Tony Saich, Governance and Politics of China, London, Palgrave Macmillan, 2010, p. 144.

16. See, for instance, Ministry of Public Security, "Jisuanji xinxi wangluo guoji lianwang anquan baohu guanli banfa" (Computer Information Network International Interconnection Security Protection Management Rules), 30 December 1997. Translation available at http://chinacopyrightand media.wordpress.com/1997/12/30/computer-information-network-international-interconnection-security-protection-management-rules. 
院信息化工作领导小组). This was chaired by Vice-premier Zou Jiahua, and included not only representatives from the economic, scientific, and technological sectors, but also from the two media departments, the PLA's General Staff Department, and the Ministry of Public Security. ${ }^{(17)}$ This Leading Group was merged into the newly established MII in 1998, but a similar group was again established the year afterwards under Vice-premier Wu Bangguo. ${ }^{(18)}$ In 2001, the group was raised from the vice-premier level to premier level, with a corresponding change in the ranks of its members. ${ }^{(19)}$ It was also given an office in charge of daily affairs, which was merged into the newly-established Ministry of Industry and Information Technology (MIIT) in 2008. As Austin argues, the focus of these institutions gradually changed from technology and an information economy to a more broadly defined notion of an information society. ${ }^{(20)}$ Still, other Party bodies had a considerable influence on Internet development as well. Concerning content, the most important of these was the Central Propaganda Department (Zhongyang xuanchuan bu 中央宣传部), which extended its control over the network through its subordinate ministries, including SARFT and GAPP, as well as the State Council Information Office (SCIO). (21)

This structure was problematic in two respects. First, it saw protracted administrative turf battles and departmental protectionism. The creation of the MII in 1998 was partly pushed by escalating tensions between the Ministry of Post and Telecommunications and the Ministry of Electronics Industry, and especially the fledgling telecommunications operators each had established. (22) It took years of intra-ministerial negotiation (23) before the State Council, in 2010, could announce concrete trial measures to integrate China's telecommunications, cable television, and Internet networks. ${ }^{(24)}$ At the time of writing, a national cable operator has been established, and a number of pilot projects have been launched, yet "three-network convergence" (sanwang ronghe 三网融合) remains more an aspiration than a reality. ${ }^{(25)}$ In the area of content, a spat over online gaming licensing privileges between GAPP and the Ministry of Culture led to a fivemonth shutdown of China's most popular online game, World of Warcraft. (26)

Yet at the same time, there were also blind spots in regulatory terms, which became particularly visible in the area of content. The propaganda system primarily considered the Internet as merely a new publishing or broadcasting platform. The main thrust of their regulatory approach was therefore a relatively simple extension of the management model and repertoire of propaganda techniques that had been developed for the online incarnations of traditional media, such as online videos, news, and blogs. Yet this approach was not adapted to the emergence of Web 2.0 applications such as microblogs and other social communication tools that facilitated novel forms of interaction. The extent to which netizens turned into content creators and the speed at which information could "go viral" seems to have come as a surprise to the authorities. The Ministry of Industry and Information Technology was in nominal charge of regulating "online information services." (27) However, MIIT was not primarily a censorship body, and the relevant regulations had not been revised since 2001. (28) Moreover, coordination between various local public security, media, and Internet information offices with regards to censorship policy was also often lacking.

Initial measures to counter this situation were already taken before the $18^{\text {th }}$ Party Congress. Most importantly, the State Internet Information Office (SIIO, Guojia hulianwang xinxi bangongshi 国家互联网信息办公室) was established in 2011. At that time, it was essentially subordinate to the SCIO and did not have independent staffing. Two full-time vice-directors were appointed in 2012. The first, Peng Bo, had a background in the publishing sector and the SCIO's Internet management department, while the second, Wang Xiujun, had been chief engineer at MIIT. The SIIO grew in stature and importance during the Xi administration's first year, in tandem with a series of campaigns aimed at bringing social media under control. Most importantly, it gained independent leadership, as Beijing municipal propaganda chief Lu Wei was appointed director in the spring of 2013. In October, he gained a third deputy named Ren Xianliang, previously a propaganda cadre in Shaanxi. Furthermore, as part of a ministerial streamlining, SARFT and GAPP merged in the summer of 2013. (29) This reduced administrative overlap and ensured that the resulting State Administration for Press, Publications, Radio, Film, and Television (SAPPRFT) would be better able to cope with a converged media environment.

Reorganisation was not limited to the executive level. In keeping with the "top-level design" (dingceng sheji 顶层设计) theme espoused in the Third Plenum, further restructuring affected leadership and coordination of cyber affairs. On 27 February 2014, the first meeting of a new central coordinating body for Internet governance took place in Beijing. The new Central Leading Group for Cybersecurity and Informatisation (Zhongyang

17. State Council General Office, "Guowuyuan bangongting guanyu chengli guowuyuan xinxihua gongzuo lingdao xiaozu de tongzhi" (State Council General Office Notice Concerning the Establishment of the State Council Leading Group for Informatisation Work), 16 April 1996.

18. There were some small changes in membership: the vice-governor of the People's Bank of China, for instance, was dropped from the 1999 iteration. A vice-minister from the Ministry of State Security was among the new additions. State Council General Office, "Guowuyuan bangongting guanyu chengli guojia xinxihua gongzuo lingdao xiaozu de tongzhi" (State Council General Office Notice Concerning the Establishment of the Leading Group for National Informatisation), 23 December 1999.

19. Wang Yukai, "Zhongyang wangluo anquan yu xinxihua lingdao xiaozu de youlai ji qi yingxiang" (The Origins of the Central Leading Group for Cybersecurity and Informatisation and its Influence), People's Daily Online, 3 March 2014, http://theory.people.com.cn/n/2014/0303/c4053124510897.html.

20. Greg Austin, Cyber Policy in China, op. cit., Ch. 1.

21. See, most notably, Anne-Marie Brady, Marketing Dictatorship: Propaganda and Thought Work in Contemporary China, Lanham, Rowman \& Littlefield, 2009; David Shambaugh, "China's Propaganda System: Institutions, Processes and Efficacy," The China Journal, No. 57, 2007, pp. 25-58.

22. Zixue Tai, The Internet in China: Cyberspace and Civil Society, Abingdon, Routledge, 2013, p. 134.

23. In 2003 already, Junhua Zhang wrote about the departmental infighting surrounding the integration of network infrastructure. Junhua Zhang, "Network Convergence and Bureaucratic TurfWars," in Christopher Hughes and Gudrun Wacker, China and the Internet: Politics of the Digital Leap Forward, op. cit., pp. 83-101.

24. State Council, "Guanyu sanwang ronghe shidian gongzuo youguan wenti de tongzhi" (Notice Concerning Questions Pertaining to Three-Network Integration Trial Point Work), 2 August 2010.

25. Shen Jingting, "China Moves to Unify Cable Firms into One Network," China Daily, 29 May 2014.

26. Nicholas Groffman, Erik Leyssens, "New Online Game Regulations Aim to Tidy Up China's Online Game Sector," Mondaq, 7 July 2010, www.mondaq.com/x/104224/Gaming/New+Online+ Game+Regulations+Aim+to+Tidy+Up+Chinas+Online+Game+Sector.

27. Guobin Yang, "Social Dynamics in the Evolution of China's Internet Content Control Regime," in Monroe E. Price, Stefaan G. Verhulst, and Libby Morgan (eds), Routledge Handbook of Media Law, New York, Routledge, pp. 285-302; Rogier Creemers, "The Privilege of Speech and New Media: Conceptualizing China's Communications Law in the Internet Era," in Jacques DeLisle, Avery Goldstein, and Guobin Yang (eds), The Internet, Social Media and a Changing China, Philadelphia, University of Pennsylvania Press, Forthcoming.

28. State Council, "Guanyu 'hulianwang xinxi fuwu guanli banfa (xiuding cao'an zhengqiu yijian gao)' de shuoming" (Explanation Concerning the "Internet Information Service Management Rules [Opinion-Seeking Version of Revision Draft]), 7 June 2012. Translation available at http://chinacopyrightandmedia.wordpress.com/2012/06/07/explanation-concerning-the-internet-information-service-management-rules-opinion-seeking-version-of-revision-draft.

29. Hogan Lovells, "Will the Merger of SARFT and GAPP End The Turf War Over Control over the Internet?", June 2013, www.hoganlovells.com/files/Publication/9e7448a7-ea0c-4ed1-8b70bc61da7648e5/Presentation/PublicationAttachment/f5997588-93f2-4bdd-bc31-ca3ce524e734/ SHALIB01-\%231083537.pdf. 
Table 1 - Central Leading Group for Cybersecurity and Informatisation Membership (30)

\begin{tabular}{|c|c|}
\hline Names & Titles \\
\hline Xi Jinping (Chair) & General Secretary, PRC President \\
\hline Li Keqiang (Vice-Chair) & Premier \\
\hline Liu Yunshan (Vice-Chair) & Chief Secretary, CCP Central Secretariat; Chairman, Central Ideology and Propaganda Leading Group \\
\hline Lu Wei (Head, Leading Group Office) & Director, Cyberspace Administration of China \\
\hline Ma Kai & Vice-Premier \\
\hline Wang Huning & Director, CCP Policy Research Office \\
\hline Liu Qibao & Director, Central Propaganda Department \\
\hline Fan Changlong & Vice Chairman, Central Military Commission \\
\hline Meng Jianzhu & Director, Central Political-Legal Committee \\
\hline Li Zhanshu & Director, CCP General Office \\
\hline Yang Jing & Secretary General, State Council \\
\hline Zhou Xiaochuan & Governor, People's Bank of China \\
\hline Wang Yi & Minister of Foreign Affairs \\
\hline Fang Fenghui & PLA Chief of Staff \\
\hline Lou Jiwei & Minister of Finance \\
\hline Cai Wu & Minister of Culture \\
\hline Yuan Guiren & Minister of Education \\
\hline Miao Wei & Minister of Industry and Information Technology \\
\hline Guo Shengkun & Minister of Public Security \\
\hline Xi Shaoshi & Chairman, National Development and Reform Commission \\
\hline Wang Zhigang & Party Secretary, Ministry of Science and Technology \\
\hline Cai Fuchao & Director, State Administration of Press, Publications, Radio, Film and Television \\
\hline
\end{tabular}

wangluo anquan he xinxihua lingdao xiaozu 中央网络安全和信息化领导小 组) was chaired by Xi Jinping himself, and its membership included departments across the spectrum of propaganda, economic management, and political affairs (See Table 1). It inherited the portfolio and membership of the previous premier-level group, with the addition of the governor of the People's Bank of China.

The Office of this new leading group, in charge of daily administrative work, was established within the SIIO, which was re-established as an independent entity and gained a new English name: Cyberspace Administration of China (CAC). In August 2014, a State Council notice announced the CAC would be responsible for the governance of all online content. (31) Subordinate technical and advisory bodies such as CNNIC, ISC, and the Advisory Council on State Informatisation now report directly to the CAC. (32) In this way, the structure of Internet governance has now taken the form of an independent xitong, resembling the propaganda system. The Leading Group and the CAC are in charge of technological and infrastructure development and security, countering cybercrime, and managing international relations in the area of cybergovernance. Illustrating this broad reach, the CAC is currently in charge of drafting a comprehensive national strategy for information technology and cybersecurity, which will provide the blueprint for policy in this area for the next decade. ${ }^{(33)}$

Some observers have suggested that this new xitong is now outstripping the traditional propaganda apparat in power and importance. ${ }^{(34)}$ Certainly, its power and position has increased significantly. The restructuring of the Leading Group means that Internet governance has been brought from the more technocratic State Council and MIIT into the centre of political decision-making. It also fits in with a broader trend to locate more authority within Party bodies rather than state bodies. Both Xi Jinping and Lu Wei have brought a more activist stance to Internet governance, in contrast with the more typical reticence of Party officials. ${ }^{(35)}$ Nevertheless, questions remain as the practical implementation of the restructuring continues. One particular matter is the authority structure between the CAC, the Leading Group, and other CCP systems. The relationship with the propaganda bureaucracy, for instance, is unclear. On the one hand, the CAC started out as a subordinate department within this system, and as vice-

30. Compiled from Guancha.cn, "Zhongyang wangluo anquan he xinxihua lingdao xiaozu chengyuan mingdan 12 zhengfu guoji jianzhi shengaizu" (Central Cybersecurity and Informatisation Leading Group Members' Name List, 12 Full and Vice-National Level [Members] also on the Leading Group for Deepening Reform), 28 February 2014, www.guancha.cn/politics/2014_02_28_209672.shtml.

31. State Council, "Guanyu shouquan guojia hulianwang xinxi bangongshi fuze hulianwang xinxi neirong guanli gongzuo de tongzhi" (Notice Concerning Empowering the Cyberspace Administration of China to be Responsible for Internet Information Content Management Work), 26 August 2014. Translation available at https://chinacopyrightandmedia.wordpress.com/2014/08/26/notice-concerning-empowering-the-cyberspace-administration-of-china-to-be-responsible-for-internet-information-content-management-work.

32. See, for instance CNNIC, "Zhongyang wangxinban xuanbu CNNIC zhuyao fuzeren renming" (Central Cyberspace Administration Announces Names of Main CNNIC Directors), 26 December 2014, www.cnnic.net.cn/gywm/xwzx/rdxw/2014/201412/t20141226_50801.htm.

33. Interview with Internet policymaker, Beijing, November 2014

34. David Bandurski, "Ali Baba's Cave and Pandora's Box," China Media Project, 5 November 2014, http://cmp.hku.hk/2014/11/05/36885.

35. For instance, a portrait of Lu Wei was published in The New York Times: Paul Mozur and Jane Perlez, "Gregarious and Direct: China's Web Doorkeeper," The New York Times, 1 December 2014. 
director of the Central Propaganda Department, Lu Wei still reports to its head, Liu Qibao, and the Standing Committee member with the propaganda portfolio, Liu Yunshan. On the other hand, as director of the CAC, Lu Wei reports directly to $\mathrm{Xi}$ Jinping. The $\mathrm{CAC}$ has also made some very visible inroads into traditional propaganda territory. In April 2015, for instance, a new research body, the Chinese Culture Institute of Internet Communication (Zhongguo wenhua wangluo chuanbo yanjiu hui 中国文化网络传播研 究会) was established under CAC authority. In foreign affairs, the CAC and the Ministry of Foreign Affairs have sent separate delegations to international cybergovernance events such as the Hague Global Conference on Cyberspace, (36) raising questions about authority structures in international affairs. The assignment of tasks, departments, and personnel between MIIT and the CAC remains in process. ${ }^{(37)}$ In other words, while the objective of this reorganisation may have been to centralise leadership power over cyber affairs, it still remains the case that the leadership will require the collaboration of individual agencies for policy implementation and execution. This, in turn, means that the perennial principal-agent and coordination issues that have plagued Internet governance thus far are likely to continue, albeit on reorganised lines.

\section{Internet policy change}

The domestic measures taken in Internet reform cannot be seen in isolation from the manner in which the Xi administration has framed its broader challenges, as well as its overall, comprehensive reform agenda. As indicated earlier, the Xi administration came to power with an agenda of countering what had become perceived as a crisis both in governing the Party and in state-society relations, as well as an increasingly hostile international environment. As a result, the techno-optimist discourse that had developed around the informatisation agenda was joined by a more security-oriented focus. Rhetorically, Internet authorities sought to portray themselves as a benevolent Leviathan preventing harm to Chinese citizens emerging from online swindles and blackmail, as well as from the social chaos that would follow from ideological destabilisation. This discourse of security was used to justify a progressive series of measures to counter potential domestic and international threats affecting online content as well as hardware and infrastructure.

\section{Content}

The expansion of Internet use in China is a well-known story. User numbers grew to 649 million at the end of 2014, and the demographic composition of Internet users shifted as rural, less well-off citizens gained access, often through mobile technology. ${ }^{(38)}$ Social media and self-media permitted individual citizens to participate in public discourse to an unprecedented extent, rendering visible political discontent, drivers for protests, and individual instances of abuse. Social media-based stories grew in prominence on the Chinese Internet, from reports on incidents such as the Wenzhou rail crash ${ }^{(39)}$ to rumours about an attempted military coup in Beijing. Also, the Internet became a platform for humorous satire and parody, exemplified by the creative use of language and imagery under the symbol of the Grass Mud Horse (caonima 草泥马). (40) Online celebrities and public intellectuals, nicknamed Big Vs, became opinion leaders, often having tens of millions of followers. ${ }^{(41)}$ The speed and extent to which information could spread on open platforms, such as social media, made it nearly impossible for management authorities to maintain control over sudden incidents and trending content.

The leadership had already started responding to these trends before the $18^{\text {th }}$ Party Congress. Online censorship gradually expanded in step with Internet usage, and the establishment of the State Internet Information Office in the same year signalled a recognition of the Internet's importance in public communication. Yet these responses were very much informed by traditional propaganda practices and tactics. For instance, the Sixth Plenum of the $17^{\text {th }}$ Party Congress was dedicated to culture and propaganda issues, but addressed Internet-related questions in only one paragraph of its comprehensive Decision. Instead, it was held that traditional persuasion- and culture-based propaganda was necessary to provide Chinese society with the necessary spiritual nourishment. The new Internet governance administration sought to tackle these perceived threats in a manner that was much more based on the characteristics of online communication. The first challenge was to defuse the tensions that had arisen on online social media and regain control. This proceeded in an ostensibly well-planned, gradual manner. In April, the Internet was identified in a secret Party document as the prime platform through which harmful information entered into public discourse. The justification for this document was provided by an acrimonious online debate about constitutionalism and the nature of CCP governance. (42) In August, the newly-appointed SIIO director Lu Wei introduced Seven Baselines (qige dixian 七个底线) for online opinion leaders, which were later expanded to all online users. Later that month, $\mathrm{Xi}$ Jinping gave a secret speech at a national conference on propaganda and ideology work where he called upon cadres to "unsheathe the sword" (liangjian 亮剑) in a new public opinion struggle with the Internet as its main battlefield. ${ }^{(43)}$ This led to a broad crackdown in which a number of Big Vs were arrested, and new rules were promulgated that imposed prison sentences on online postings that were retweeted 500 times or more. ${ }^{(44)}$ These measures explicitly targeted the volatility and publicity of a medium like Weibo, and hastened an exodus from public microblogging platforms to private messaging apps. Weibo use dropped precipitously in the space of a mere month. ${ }^{(45)}$ Having thus dealt with the primary problem, the leadership moved to consolidate a new regulatory model for social media and news. Furthermore, regulations concerning online culture

36. Interviews with conference attendees and organisers on site.

37. Interview with Internet policymaker, Beijing, April 2015.

38. CNNIC, "Di 35 ci Zhongguo hulian wangluo fazhan zhuankuang tongji baogao" (35 th Statistical Report on the Development Situation of China's Internet), January 2015.

39. Maria Bondes and Günter Schucher, "Derailed Emotions: The Transformation of Claims and Targets during the Wenzhou Online Incident," Information, Communication \& Society, Vol.17, No. 1, 2014, pp. 45-65.

40. Bingchun Meng, "From Steamed Bun to Grass Mud Horse: E Gao as Alternative Political Discourse on the Chinese Internet," Global Media and Communication, Vol. 7, No. 1, 2011, pp. 33-51.

41. Marina Svensson, "Voice, Power and Connectivity in China's Microblogosphere: Digital Divides on SinaWeibo," China Information, Vol. 28, No. 2, 2014, pp. 168-188.

42. Rogier Creemers, "China's Constitutionalism Debate: Content, Context and Implications," The China Journal, No. 74, 2015, pp. 91-109.

43. The speech itself remains unpublished. A summary was later obtained by China Digital Times. See also n. 4.

44. Supreme People's Court, "Guanyu banli liyong xinxi wangluo shishi feibang deng xingshi anjian shiyong falü ruogan wenti de jieshi" (Interpretation Concerning Some Questions of Applicable Law When Handling Uses of Information Networks to Commit Defamation and Other Such Criminal Cases), 6 September 2013, https://chinacopyrightandmedia.wordpress.com/2013/09/06/interpretation-concerning-some-questions-of-applicable-law-when-handling-uses-of-informationnetworks-to-commit-defamation-and-other-such-criminal-cases.

45. Malcolm Moore, "China Kills Off Discussion on Weibo after Internet Crackdown," Daily Telegraph, 30 January 2014, www.telegraph.co.uk/news/worldnews/asia/china/10608245/China-kills-offdiscussion-on-Weibo-after-internet-crackdown.html. 
were strengthened as well. The following sections will address these sectors in detail.

Social media and news: The reforms in the area of social media had two main focal points. First, official voices were to gain more prominence in the online sphere, while non-official voices were to be co-opted into subscribing to the "Seven Baselines." Second, rules concerning real-name registration were strengthened and, in contrast to earlier periods, more strongly enforced. ${ }^{(46)}$ Such rules directly counter online anonymity, making it easier to identify and prosecute sources of unwanted content.

As the ideological campaign deepened in 2013, more and more users left the public Weibo platform in favour of Tencent's WeChat service. ${ }^{(47)}$ For most users, WeChat is a much more private environment, with a maximum chat group size of 100 members. This means that while information can still circulate, it does so more slowly, and out of the public view. ${ }^{(48)}$ It is also possible to register for a public account, but these are limited to one message per day - limiting the potential of non-Party voices to take a leading role in public debates. Yet these limitations did not forestall further government intervention and regulation. In March, dozens of politically active public accounts across the ideological spectrum were deleted, including those belonging to liberal-leaning organisations such as Phoenix WebMedia (Fenghuang weimeiti 凤凰微媒体) and the leftist website Utopia (Wuyouzhixiang 乌有之乡). ${ }^{(49)}$ New rules on instant messaging services introduced in August 2014 imposed mandatory real-name registration obligations for all users. These rules also require instant messaging companies to examine all applications for a public account, and categorise them according to the sort of information they would disseminate. The dissemination of current affairs-related information and news was only permitted to specific licensed bodies, and no other public account holders were permitted to publish or retweet such content. ${ }^{(50)}$ The real-name registration elements of these rules were deepened in early 2015 , in regulations that also required users of all account-based online information services to commit to the Seven Baselines and the well-known list of prohibited content categories that had been included in all important media regulations. ${ }^{(51)}$ The Supreme People's Court furnished a further incentive for websites to maintain realname registration information by imposing liability on service providers who are unable to provide the identity and contact method of defendants in Internet-related tort cases. ${ }^{(52)}$

As these new regulations curtailed the activities of posters not associated with official Party media, official voices moved in to take their place. As early as April 2013, Ren Xianliang, a Shaanxi provincial propaganda official who would shortly after be promoted to Lu's deputy, had developed a theory of "two public opinion fields," the traditional media field of Party outlets, and the new media field emerging on the Internet. In Ren's diagnosis, chaos reigned in the Internet sphere, and traditional media were castigated for failing to adapt to new circumstances. ${ }^{(53)}$ In April 2014, Central Propaganda Department head Liu Qibao announced a plan for the convergence of traditional media with the online environment, and guiding opinions to this effect were passed by the Central Leading Group for the Comprehensive Deepening of Reform in August. ${ }^{(54)}$ As put in a People's Daily editorial published on the same date, "Media communication work essentially is the work of creating people's thoughts. Invisible propaganda is the most brilliant communication. Coercion is ineffective; only by bringing life as the spring breeze and rain, by silently watering everything is it possible to reach people's hearts." (55) In order to achieve these objectives, traditional media enterprises were to employ methods particularly aimed at the mobile Internet, such as building apps, to better reach their intended audiences. In connection with this, new rules also regulated journalism in online news outlets, clearly defining which kinds of online platform and their staff could produce current affairs-related content. (56)

The assessment of these measures in the Party press has been largely positive. By the end of 2014, People's Daily reported that the "consensus" in the two public opinion fields had greatly strengthened. ${ }^{(57)}$ A report of the People's Daily Public Opinion Monitoring Office published in June 2015 claimed that the positions of official mainstream media and public opinion had increasingly converged, there was an increasing degree of approval for the government, and that the online public opinion ecology had been put on "the right track" (zhenggui 正轨). ${ }^{(58)}$ At the moment, strong academic scrutiny of the reshaped social media environment in China is lacking. Nevertheless, it seems to be the case that the optimistic tone of these official

46. On the difficulties with real-name registration enforcement, see Johan Lagerkvist, "Principal-Agent Dilemma in China's Social Media Sector? The Party-State and Industry Real-Name Registration Waltz," International Journal of Communication, Vol. 6, No. 19, 2012, pp. 2628-2646.

47. "From Weibo to WeChat," The Economist, 18 January 2014, www.economist.com/news/china/ 21594296-after-crackdown-microblogs-sensitive-online-discussion-has-shifted-weibo-wechat.

48. There are, however, indications of government monitoring of WeChat. The activist $\mathrm{Hu}$ Jia, for instance, claimed security services sometimes base interrogations on WeChat conversations. John Kennedy, "Hu Jia Explains Why Mobile Apps Make Activism Spooky," South China Morning Post, 15 November 2012, www.scmp.com/comment/blogs/article/1083025/hu-jia-explains-why-mobile-apps-make-activism-spooky.

49. Tyler Roney, "China's Sudden WeChat Crackdown," The Diplomat, 14 March 2014, http://thediplomat.com/2014/03/chinas-sudden-wechat-crackdown.

50. These regulations have become popularly known as the "Ten Articles on WeChat" (Weixin shitiao). CAC, "Jishi tongxin gongju gongzhong xinxi fuwu fazhan guali zanxing guiding" (Provisional Regulations for the Development and Management of Instant Messaging Tools and Public Information Services), 7 August 2014, https://chinacopyrightandmedia.wordpress.com/2014/08/07/provisional-regulations-for-the-development-and-management-of-instant-messaging-tools-and-public-information-services.

51. CAC, "Hulianwang yonghu zhanghao mingcheng guanli guiding" (Internet User Account Name Management Regulations), 4 February 2015, https://chinacopyrightandmedia.wordpress.com/ 2015/02/04/internet-user-account-name-management-regulations.

52. Supreme People's Court, "Guanyu shenli liyong xinxiwangluo qinhai renshen quanyi minsji jiufen anjian shiyong falü ruogan wenti de guiding" (Regulations Concerning Some Questions of Applicable Law in Handing Civil Dispute Cases Involving the Use of Information Networks to Harm personal Rights and Interests), 9 October 2014, https://chinacopyrightandmedia.wordpress.com/ 2014/10/09/supreme-peoples-court-regulations-concerning-some-questions-of-applicable-lawin-handing-civil-dispute-cases-involving-the-use-of-information-networks-to-harm-personalrights-and-interests.

53. Ren Xianliang, "Tongchou liangge yulunchang, ningju shehui zheng nengliang" (Comprehensively Plan Both Public Opinion Fields, Concentrate Society's Positive Energy), Red Flag Manuscripts, No. 2013/07. Translation available at https://chinacopyrightandmedia.wordpress.com/2013/04/24/ propaganda-directors-call-to-traditional-media-wake-up.

54. Central Leading Group for the Comprehensive Deepening of Reform, "Guanyu tuidong chuantong meiti he xinxing meiti ronghe fazhan de zhidao yijian" (Guiding Opinions Concerning the Converged Development of Traditional Media and New Media), 18 August 2014.

55. Guo Ping, "Zai meiti ronghe xin geju zhong jianghao Zhongguo gushi" (People's Daily: Telling China's Story Well in a New Converged Media Structure), People's Daily, 19 August 2014. Translation available at https://chinacopyrightandmedia.wordpress.com/2014/08/19/peoples-dailytelling-chinas-story-well-in-a-new-converged-media-structure.

56. SAPPRFT, CAC, "Guanyu zai xinwen wangzhan hefa xinwen jizhezheng de tongshi" (Notice Concerning Approving and Issuing Journalist Credentials in News Websites), 21 October 2014. Translation available at https://chinacopyrightandmedia.wordpress.com/2014/10/21/noticeconcerning-approving-and-issuing-journalist-credentials-in-news-websites.

57. CAC, "2014 nian 'liangge yulunchang' gongshidu zengqiang" (Degree of Consensus Strengthening in the "Two Public Opinion Fields" in 2014), www.cac.gov.cn/2014-12/26/c_1113787892_2.htm.

58. Liu Pengfei, Zhou Yaqiong, and Zhang Li, "2014 nian Zhongguo yidong yulunchang yuqing fazhan baogao" (2014 Report on the Development of Public Sentiment in China's Mobile Public Opinion Sphere), in Tang Xujun (ed.), Xin meiti lanpishu: Zhongguo xinmeiti fazhan baogao No. 6 (Blue Book of New Media: Annual Report on Development of New Media in China No. 6), Beijing, Shehui kexue wenxian chubanshe, 2015 
reports is not wholly undeserved. While some forms of satire and online banter persist, social media no longer seem to be the political crucible they were before the $18^{\text {th }}$ Party Congress. To a certain degree, this may be ascribed to the high levels of stress and tensions associated with the Xi administration's unrelenting anti-corruption and anti-dissent campaigns. Nevertheless, it remains to be seen whether this will remain the case as political circumstances change - as they inevitably must - in the future.

Online culture: Perhaps somewhat counterintuitively, the prominence of cultural propaganda seems to have diminished somewhat in the effort to regain dominance over online public opinion. Maria Repnikova and Kecheng Fang suggest that, having dispensed with classical state-sponsored, top-down cultural products, the new leadership has adopted a much more participatory approach to online persuasion. ${ }^{(59)}$ Nevertheless, the traditional cultural bureaucracies, particularly SAPPRFT, have sought to maintain at least some level of influence and authority in this sphere. In particular, it has focused its attention on online video and literature.

In January, SAPPRFT issued a notice outlining its intention to strengthen respective management over online video. This document obliged producers to obtain the correct licensing, and imposed producer-like liabilities onto online video platforms for content produced by individuals. As part of this, video websites were required to obtain the real identity of such producers. ${ }^{(60)}$ In September, SAPPRFT formally enacted new procedures for censorship of foreign audio-visual content. There had been an obligation to license imported works used in online broadcast for many years, but this was honoured more in the breach than in the observance. The new rules mandated that online video providers had to file annual import plans for approval, that every newly-imported film or television programme had to undergo content inspection, and that all relevant information had to be uploaded to an online registration platform, managed by SAPPRFT. Furthermore, this document introduced an import quota: online video platforms were only permitted to import a quantity of foreign content equivalent to $30 \%$ of the domestically produced content they purchased the preceding year. ${ }^{(61)}$ Later that month, SAPPRFT issued a notice indicating that videos featuring stars and celebrities with convictions for drug use, solicitation, or other crimes could no longer be broadcast. In November, it published regulations proscribing, amongst others, one-night stands and extramarital affairs in online videos. ${ }^{(62)}$

SAPPRFT also intensified the annual campaigns fighting pornography and other unlawful content online. The 2014 "Clean the Web" (Jingwang 净网) campaign attracted worldwide headlines when popular and ostensibly harmless television series such as The Big Bang Theory were banned from Chinese video websites. Sina lost its audio-visual broadcasting licence after pornographic content was discovered on some of its services. The small number of works at issue, four videos and 20 articles, suggests that this move might have wider motives. Equally, the fact that the banned, highly popular series were later broadcast in an edited version by CCTV (63) indicates that state-owned entities may have taken advantage of political circumstances for economic gain. As the campaign deepened, SAPPRFT broadened its focus to set-top boxes and mobile video apps. ${ }^{(64)}$ It also called in the seven TV stations holding online television licences for a criticism meeting, at which it ordered the withdrawal of all unapproved foreign channels that these stations broadcast. ${ }^{(65)}$ Lastly, it went after popular platforms for the distribution of crowdsourced subtitles, including YYeTs and Shooter.cn, in a further bid to reduce the market presence of foreign programmes. ${ }^{(66)}$ However, Chinese programmes were targeted as well, as illustrated by the fact that a popular historical drama on the Tang Dynasty empress Wu Zetian was pulled from screens, allegedly because of excessive cleavage. ${ }^{(67)}$ The Ministry of Culture also played a part in the campaign, announcing punishments for firms including Tencent and Baidu for the spread of pornographic and gambling games. ${ }^{(68)}$

While the stress on traditional propaganda approaches was reduced, it did not disappear from the leadership's radar. In October, a Forum on Literature and Art took place in Beijing. In his speech at this event, Xi Jinping stressed a more conservative, Party-oriented approach to art, calling for "even more excellent works that disseminate the value views of present-day China, reflect the spirit of Chinese culture, mirror the aesthetic pursuits of Chinese people, and organically integrate ideology, artistry, and enjoyability." (69) While his speech, or at least the edited version of it reported by Xinhua, did not directly reference the Internet, SAPPRFT responded to this speech at the end of December, with a development plan for the hugely successful online literature industry. This had hitherto remained under the regulatory radar, but online literature enterprises would now come under closer regulatory scrutiny, with increasing stress on ideological rectitude and the eulogy of a particular top-down defined vision of Chinese culture. In particular, the role of literary commentary and criticism would be strengthened, while authors would be subject to a real-name registration system.

59. Maria Repnikova and Kecheng Fang, "Behind the Fall of China's Greatest Newspaper: Censorship and Commercial Pressures Have Driven the Once-Revered Southern Weekly to the Margins," Foreign Policy, 29 January 2015, https://foreignpolicy.com/2015/01/29/southern-weekly-chinamedia-censorship/ (accessed on 21 November 2015).

60. SAPPRFT, "Guanyu jinyibu wanshan wangluoju, weidianying deng wangluo shiting jiemu guanli de buching tonghi" (Supplementary Notice Concerning Further Perfecting the Management of Online Dramas, Microfilms and Other Such Online Videos), 2 January 2014. Translation available at https://chinacopyrightandmedia.wordpress.com/2014/01/02/supplementary-notice-concerningfurther-perfecting-the-management-of-online-dramas-microfilms-and-other-such-online-videos.

61. SAPPRFT, "Guanyu junyibu luoshi wangshang jingwai yingshiju guanli youguan guiding de tongzhi" (Notice Concerning Further Implementing Regulations on the Management of Online Foreign Film and Television Dramas), 2 September 2014. Translation available at https://chinacopyrightandmedia.wordpress.com/2014/09/02/notice-concerning-further-implementing-regulationson-the-management-of-online-foreign-film-and-television-dramas.

62. SAPPRFT, "Guanyu jiaqiang youguan guangbo dianshi jiemu, yingshiju he wangluo shiting jiemu zhizuo chuanbo guanli de tongzhi" (Notice Concerning Strengthening Management of the Production and Dissemination of Radio, Film and Television Programmes, Television Dramas and Online Audiovisual Products), 28 September 2014. Translation available at https://chinacopyrightand media.wordpress.com/2014/09/28/notice-concerning-strengthening-management-of-the-production-and-dissemination-of-radio-film-and-television-programmes-television-dramas-and-online-audiovisual-products.

63. "CCTV to Broadcast 'The Big Bang Theory,"' People's Daily Online, 30 April 2014, http://en. people.cn/98649/8614399.html (accessed on 30 October 2015).

64. "Guangdian zongju zhengdun hulianwang dianshihe: yaoqiu guanbi shipin APP" (SAPPRFT Rectifies Internet Television Boxes: Demands Closure of Audio-Visual Apps), Sina.com, 24 June 2014, http://tech.sina.com.cn/i/2014-06-24/09089455612.shtml.

65. "Guangdian zongju yuetan qipai zhaoshang: wu zizhi jingwai yingshiju yizhounei xiaxian" (SAPPRFT Meets Seven License Holders: Unlicensed Foreign Television Dramas to Be Taken Off-Line Within One Week), Ifeng.com, 15 July 2014, http://tech.ifeng.com/speakout/detail_2014_07/ 15/37345736_0.shtml.

66. "As China Cracks Down on Illegal Videos, Lovers of Foreign TV Mourn," Wall Street Journal, 25 November 2014, http://blogs.wsj.com/chinarealtime/2014/11/25/as-china-cracks-down-on-illegalvideos-foreign-tv-lovers-mourn.

67. Amy Qin, "A Historical Drama Shows Too Much Cleavage for China's Censors," The New York Times, 2 January 2015, http://sinosphere.blogs.nytimes.com/2015/01/02/a-historical-drama-shows-toomuch-cleavage-for-chinas-censors.

68. "China Punishes Internet Firms for Spreading Porn," Xinhuanet, 2 December 2014, http://news.xinhuanet.com/english/china/2014-12/02/c_133828482.htm.

69. "Xi Jinping: wenyi buneng zai shichang jingji dachao zhong mishi fangxiang" (Xi Jinping: Literature and Art Cannot Lose Their Way in the Wave of the Market Economy), Xinhua, 15 October 2014, https://chinacopyrightandmedia.wordpress.com/2014/10/16/xi-jinpings-talks-at-the-beijingforum-on-literature-and-art. 


\section{Technological security}

In conjunction with the content regulation reforms outlined above, significant attention has also been directed at the extent to which China's reliance on foreign technology might provide channels for infiltration and subversion by "foreign hostile powers." In spite of plans existing since the 1980s (in particular the 986 project), China still relies on foreign suppliers for the absolute majority of its hardware and software. This was thrown in painful relief through events such as the discontinuation of support for Windows XP in April 2014 and the Snowden revelations, which created considerable concern about China's perceived inability to stand up to the technological superiority of, in particular, the United States. ${ }^{(70)}$ Red Flag Magazine, for instance, published an article in which individuals from $\mathrm{Na}$ tional Defence University warned about the possibility of solar-powered drones off the coast of China providing connectivity to dissidents in the coastal regions. ${ }^{(71)}$

In response, the leadership initiated a broader push to speed up the Sinification of ICT resources and to gain more influence over the products and services of US technology companies. One raft of measures was taken days after US Department of Justice indicted five PLA officers associated with the Shanghai-based unit 61398, which was identified as the perpetrator of consistent cyberespionage attacks in the 2013 Mandiant Report. On one day, 27 May, reports emerged that a proposal to review the security of server equipment in the financial sector would be submitted to the Central Leading Group, ${ }^{(72)}$ that state-owned enterprises (SOEs) were required to sever ties with foreign consulting companies due to suspicion that the latter conducted intelligence-gathering on behalf of the US government, and that the People's Bank of China and the Ministry of Finance were encouraging banks to replace IBM servers with domestic hardware. On the same day, the server manufacturer Inspur announced a plan to replace IBM hardware in the small server market. ${ }^{(73)}$ Furthermore, mere days after the indictment was announced, the Chinese government procurement authorities announced that the purchase of computer hardware running the Windows 8 operating system would be prohibited. ${ }^{(74)}$

In the area of software, 2014 saw the release of a new mobile operating system, the Linux-based China Operating System. This was developed by the Chinese Academy of Sciences and the Shanghai-based Liantong Network Communications Technology. It was announced that the system was tested on China Mobile and China Telecom networks, was compatible with Java and HTML5, and supported more than 100,000 existing applications. According to Chen Feili, a deputy general manager of Liantong, the ultimate objective is to make COS into China's main operating system, and to broaden its reach to laptop and desktop platforms. (75) But COS is not alone. Also in January, Coship Electronics launched its native mobile operating system 9600S, (76) while progress was also announced on Ubuntu Kylin, (77) a desktop OS developed by a UK software firm under the auspices of the Ministry of Industry and Information Technology. Advances were also made in server hardware. The firm Sugon, previously known for its production of supercomputers, announced that it had successfully developed and manufactured servers based on the Long Xin 3B eight-core processor. ${ }^{(78)}$ It is claimed that this processor, whose intellectual property rights are wholly Chinese, will be included in hardware in the military, financial, and other sectors, and reduce China's reliance on imported microchips.

Together with these import substitution measures, the government also threw up increasing regulatory barriers for foreign technology. In
May, the CAC announced a comprehensive security review system for "important technologies and services used in systems concerning national security and the public interest." (79) In December, Apple CEO Tim Cook agreed with Lu Wei that Apple's products would be subject to these security audits. However, foreign technology companies and commercial associations also protested against new regulations issued by China's banking regulator. These require companies selling computer equipment to Chinese banks to submit source codes and provide back doors into hardware and software. Furthermore, $75 \%$ of technology products used in Chinese financial institutions must become "secure and controllable" by 2019. (80) In the area of government procurement, a number of US technology firms were removed from approved government procurement purchasing lists, most prominently affecting the sales of Cisco equipment. (81) Unsurprisingly, these measures have attracted mixed responses from foreign observers, in particular the Western companies that see their business threatened through import substitution preferences.

The government also launched broader initiatives in the area of cybersecurity, with a particular focus on the security of mobile applications. A campaign targeting mobile malware started in April, ${ }^{(82)}$ while in August, MIIT published a comprehensive security plan for the online environment. ${ }^{(83)}$ This plan not only called for more effectively controllable software and hardware, but also for better personal data protection and better security management for app stores. A first cybersecurity week was organ-

70. The cessation of support for Windows XP was listed second in a summary of "cybersecurity events" in 2014 by Internet company NetEase. "2014 nian Zhongguo shida wangluoanquan shijian pandian" (Ranking the Top Ten Cybersecurity Events in China for 2014), NetEase, 10 December 2014, http://digi.163.com/14/1210/13/AD3V32UV001618JV.html.

71. Zhao Zhoujian, Xu Zhilian, "Xinxi jishu fazhan yu yishixingtai anquan" (Information Technology Development Trends and Ideological Security), Red Flag Manuscript, No. 2014/24, 2014. Translation available at https://chinacopyrightandmedia.wordpress.com/2015/01/01/information-technology-development-trends-and-ideological-security.

72. "China Said to Study IBM Servers for Bank Security Risks," Bloomberg, 27 May 2014, www.bloomberg.com/news/articles/2014-05-27/china-said-to-push-banks-to-remove-ibmservers-in-spy-dispute.

73. Clark Edward Barrett, "China's "Server Sinification" Campaign for Import Substitution: Strategy and Snowden (Part 2)," China Brief, Vol. 15, No. 2, 2015

74. "China Bans Use of Microsoft's Windows 8 on Government Computers," Reuters, www.reuters.com/article/2014/05/20/us-microsoft-china-idUSBREA4J07Q20140520.

75. Bree Feng, "China Unveils New Native Operating System," The New York Times, 17 January 2014, http://sinosphere.blogs.nytimes.com/2014/01/17/china-unveils-new-native-operating-system.

76. "China Unveils Native Mobile Operating System," Xinhua, 9 January 2014, http://news. xinhuanet.com/english/china/2014-01/09/c_133032451.htm.

77. "Ubuntu Kylin Announces Hardware Deal with HP in China," OMG Ubuntu, 16 May 2014, www.omgubuntu.co.uk/2014/05/ubuntu-kylin-oem-partners-announced.

78. Michael Kan, "China Develops Its Own Homegrown Servers Amid Cybersecurity Concerns," Computer World, 24 October 2014, www.computerworld.com/article/2838023/servers/china-develops-its-own-homegrown-servers-amid-cybersecurity-concerns.html.

79. "Woguo jiang chutai wangluo anquan shencha zhidu" (Our Country Will Unveil a Cybersecurity Inspection System), People's Daily, 23 May 2014

80. Paul Mozur, "New Rules in China Upset Western Tech Companies," The New York Times, 28 January 2015, www.nytimes.com/2015/01/29/technology/in-china-new-cybersecurity-rules-perturbwestern-tech-companies.html?_r=0.

81. Simon Denyer, "China Removes Top US Tech Firms from Government Purchasing List," Washington Post, 27 February 2015, www.washingtonpost.com/world/china-bars-top-us-technology-firmsfrom-government-list/2015/02/26/ebd4282c-bda1-11e4-9dfb-03366e719af8_story.html.

82. MIIT, "Daji zhili yidong hulianwang eyi chengxu zhuanxiang xingdong gongzuo fang'an" (Work Plan for the Special Campaign to Attack and Deal with Malicious Software on the Mobile Internet," 15 April 2014.

83. MIIT, "Guanyu jiaqiang dianxin he hulianwang hangye wangluo anquan gongzuo de zhidao yixian" (Guiding Opinions Concerning Strengthening Cybersecurity Work in the Telecommunications and Internet Sectors), 28 August 2014. Translation available at https://chinacopyright andmedia.wordpress.com/2014/08/28/guiding-opinions-concerning-strengthening-cybersecurity-work-in-the-telecommunications-and-internet-sectors. 
ised in October 2014 in order to raise the population's awareness about personal data protection and online fraud, as well as harmful information. In the wake of this event, a self-regulatory convention for informationbased apps was promulgated in Beijing. ${ }^{\left({ }^{84}\right)}$ A draft anti-terrorism law, promulgated in November, also required that data concerning telecommunications and Internet services must remain within the borders of China. ${ }^{(85)}$ But perhaps the most influential measure in the long run will be the social credit system announced in June. The ultimate objective for this system is to use big data to measure citizens' trustworthiness across a range of indicators, including online discipline. ${ }^{(86)}$ This would not merely be a tool for surveillance, but also a digital Panopticon-like stimulant for netizens' self-restraint.

\section{Conclusion}

To recapitulate, 2014 was a pivotal year for cybergovernance in China in many ways. It saw an institutional reconfiguration with the intention of overcoming departmental boundaries and creating direct links between central authority and the levers of cyber power. A much more ambitious tack was taken in terms of content governance as well as control over technologies and suppliers. China also strengthened its international presence, making its agenda more prominent and building a modicum of support among other nations.

These changes are not important for their content per se; few of the measures and initiatives announced and undertaken were completely new. The groundwork for both the CAC and the Leading Group was laid in the previous decade. The technological indigenisation plans draw back on a development programme, the 863 Programme, initiated in 1986. ${ }^{(87)}$ Realname registration has been an aspiration for at least a decade. ${ }^{(88)}$ The social media crackdown can be drawn back to the Sixth Plenum of 2011, and even to patterns of censorship and communication management drawing back to the Democracy Wall movement in 1979. The online literature development plan reads mostly like the development plans for other cultural industries that have been published over the last ten years.

What has changed, however, is the importance that information technology has in the eyes of the central leadership in many areas of social control, political reform, and economic development. Informatisation is no longer seen as an add-on to traditional policy tools and practices, but as a core facilitator of a new governance approach based on ubiquitous sensors, IT terminals, big data, and cloud storage. This approach is illustrated in the social credit scheme, which leverages data generated at multiple points to create a new structure for behavioural "nudging." (89)

Yet the realisation of these bold objectives may prove difficult. A first problem is that bureaucratic interests continue to diverge. While the creation of the Central Leading Group and the CAC ensures that all bureaucracies involved in Internet governance are at least sitting around the same table, considerable differences of opinion concerning strategy and policy remain. The leadership's attitude against Internet corporations remains ambivalent. On the one hand, China's Internet giants are presented as national champions and examples of China's growing capacity for innovation. Yet on the other hand, they are regularly and publicly tapped on the fingers for small offences. Recently, central Party media criticised the dominant presence of the three giants Baidu, Alibaba, and Tencent as an oligopoly that impeded the emergence of new industry entrants and fostered anti-competitive behaviour. ${ }^{(90)}$
But perhaps most crucially, the importance of the CAC seems to fluctuate. With the reform of online content regulation largely complete, its prominence in cyber policy-making has diminished in comparison to the State Council and the National People's Congress. The Internet Plus agenda, and the subsequent development plans for the e-commerce, egovernment, and big data sectors originate from the State Council and contain few references to the CAC. In the explanatory document for the Cybersecurity Law draft published in the summer of 2015, the NPC only mentioned in passing that the CAC had been part of an international consultation process. In the meantime, the announced new national cyberstrategy has not been published, in part due to continued debate on whether its orientation should be primarily to foster economic and commercial development or to ensure ideological and technological security. ${ }^{(91)}$ It thus seems that, like the broader situation, China's Internet governance regime will remain unsettled for the near future.

I Rogier Creemers is a departmental lecturer in the politics and history of China at the Department of Politics and International Relations, and the China Centre, at Oxford University Oxford OX2 6LU, UK (rogier.creemers@politics.ox.ac.uk).

84. Capital Internet Association, "Beijing shi yidong hulianwang yingyong chengxu gongzhong xinxi fuwu zilü gongyue" (Beijing Municipality Self-Discipline Convention on Internet Application Programmes and Public Information Services), 26 November 2014. Translation available at https://chinacopyrightandmedia.wordpress.com/2014/11/26/beijing-municipality-self-discipline-conventio n-on-internet-application-programmes-and-public-information-services.

85. NPC, "Fan kongbuzhuyi fa (cao'an)" (Anti-Terrorism Law [Draft]), 3 November 2014.

86. State Council, "Shehui xinyong tixi jianshe guihua gangyao (2014-2020 nian)" (Planning Outline for the Construction of a Social Credit System [2014-2020]), 14 June 2014.

87. This program has now become an important bureaucracy and funder for scientific research.

88. "China's Real Name Internet Part 1: Ancient History - 2003 to Early 2012," Fei Chang Dao, 8 August 2014, http://blog.feichangdao.com/2014/08/chinas-real-name-internet-part-1.html.

89. Cass Sunstein and Richard Thaler, Nudge: Improving Decisions About Health, Wealth, and Hapiness, New Haven, CT, Yale University Press, 2008.

90. "China Focus: Is China in an Age of Internet Oligopoly?" Xinhua, 30 January 2015, http://news.xinhuanet.com/english/sci/2015-01/30/c_133959669.htm.

91. Interview with Internet policymaker, Beijing, October 2014 